УДК 635.64:631.581.19

https://doi.org/10.32634/0869-8155-2020-341-9-102-105

ТТип статьи: Оригинальное исследование

Type of article: Original research

Алиева И.Ш.,

Агаев Ф.Н.

Научно-исследовательский институт овощеводства

Азербайджан, г. Баку, пос. Пиршаги,

СОВхоз №2

E-mail: teti_az@mail.ru

Ключевые слова: томат, сорт, растение, биохимический состав, биоморфологические показатели устойчивость, урожайность.

Для цитирования: Алиева И.Ш. Агаев Ф.Н. Новые сорта томата, районированные в условиях Азербайджанской республики. Аграрная наука. 2020; 341 (9): 102-105.

https://doi.org/10.32634/0869-8155-2020-341-9-102-105

Конфликт интересов отсутствует

Irada Sh. Aliyeva,

Fakhraddin N. Agayev

Scientific Research Institute of Vegetable Growing

ku, Pirshagi settlement, state farm No. 2

E-mail: teti_az@mail.ru

Key words: tomato, variety, plant, biochemical composition, biomorphological indicators, resistance, yield.

For citation: Aliyeva I.Sh., Agayev F.N. New varieties of tomato, zoned in the conditions of the Republic of Azerbaijan. Agrarian Science. 2020; 341 (9): 102-105. (In Russ.)

https://doi.org/10.32634/0869-8155-2020-341-9-102-105

There is no conflict of interests
Новые сорта томата, районированные в условиях Азербайджанской республики

\section{PEЗЮME}

Актуальность и материал. В статье дана краткая характеристика 5 новых районированных сортов томата для открытого грунта в условиях Азербайджанской республики. Это сорта: Зарраби, Нуру, Юбилей-60, Азербайджан-94, Мирвари. Новые сорта являются результатом совместной работы лаборатории селекции с сектором иммунитета, которая проводилась на основе общепринятой методики ВИР им. Н.И.Вавилова.

Результаты. Установлено, что новые сорта томата отличаются высокой урожайностью и высоким качеством плодов, сорта раннеспелые и среднеранние, устойчивы к болезням, вредителям и абиотическим факторам внешней среды, таким как засуха, высокая температура и низкая влажность воздуха. Биохимический состав: сухое вещество - 5,0-6,8\%, сумма сахаров - 2,4-3,3\%, общая кислотность - 0,22-0,40\%, аскорбиновая кислота - 25,0-30,6 мг/100 г, нитраты - 4560 мг/кг. Наибольшим содержанием сухого вещества $(6,2-6,8 \%)$ и общего сахара (2,6-3,3\%) отличались сорта Азербайджан-94 и Мирвари. Новые районированные сорта Азербайжан-94 и Мирвари также выделялись по показателям урожайности по сравнению с другими сортами: 624,4-633,9 ц/га и 612,0-625,2 ц/га, соответственно. Сорта Нуру и Азербайджан-94 - высокорослые, хорошо облиствены, крупноплодные. Сорта предназначены для потребления в свежем виде и для промышленной переработки с целью получения высококачественных пищевых продуктов.

\title{
New varieties of tomato, zoned in the conditions of the Republic of Azerbaijan
}

\section{ABSTRACT}

Relevance and material. The article gives a brief description of 5 new zoned varieties of tomato for open ground in the conditions of the Republic of Azerbaijan. These are the varieties: Zarrabi, Nuru, Jubiley-60, Azerbaijan-94, Mirvari.

Results. It has been established that new varieties of tomato are distinguished by high yield and high quality of fruits, early and medium-early varieties, resistant to diseases, pests and abiotic environmental factors such as drought, high temperature and low air humidity. Biochemical composition: dry matter $-5.0-6.8 \%$, the amount of sugars $2.4-3.3 \%$, total acidity - 0.22-0.40\%, ascorbic acid - 25.0-30.6 mg/100 g, nitrates $45-60 \mathrm{mg} / \mathrm{kg}$. The highest content of dry matter (6.2-6.8\%) and total sugar (2.6-3.3\%) was observed for varieties Azerbaijan-94 and Mirvari. New varieties Azerbayzhan-94 and Mirvari stood out in terms of yield compared to other varieties: 624.4-633.9 centners / ha and 612.0-625.2 centners/ha. 


\section{Введение}

Азербайджан является одной из древних и богатых растительными ресурсами стран мира. Растительный покров республики составляет около 70\% флоры Кавказа. В этом регионе произрастает более 4500 видов растений в т. ч., более 200 видов овощных и плодовых культур [1].

Азербайджанская Республика характеризуется исключительно благоприятными условиями для развития овощеводства открытого грунта, и особенно раннего. Обилие солнечного света и тепла, мягкий климат и плодородие почв Кура-Араксинской и Прикаспийской низменностей обеспечивают широкие возможности для организации здесь в открытом грунте промышленного овощеводства Однако, несмотря на древнюю историю возделывания овощей, наличие необходимых условий и огромную значимость продуктов овощеводства в питании населения, эта отрасль развивалась медленно и носила весьма ограниченный потребительский характер [1].

Промышленное овощеводство в Азербайджане начало развиваться только в годы Советской власти в связи с индустриализацией республики и своего бурного развития оно достигло в 1960-1980 годы.

Томат - наиболее широко распространённая и самая приоритетная культура среди овощных, возделываемых в республике.

Наличие благоприятных почвенно-климатических условий и высокая экологическая пластичность сортов томата позволяют выращивать их повсеместно и на больших площадях во всех овощеводческих зонах Круглогодичное использование населением плодов томата, поступающих с открытого грунта, требует непрерывного роста площадей этой культуры, и поэтому неслучайно, что она составляет одну треть $(33,3 \%)$ общей площади, занятой под всеми овощными культурами. За последние годы производство томатов составило более 44,5 \% от общей валовой продукции овощей, в средняя урожайность с гектара значительно превосходит другие овощные культуры [4]

\section{Материалы и методы исследовании}

Главной задачей овощеводов республики является производство высокоурожайных, высококачественных и устойчивых к болезням и вредителям, а также к абиотическим факторам среды сортов и гибридов овощных культур. Для выполнения поставленной задачи в селекционную работу с основными овощными культурами, в т. ч. и с томатом, вовлекался и использовался огромный генофонд местного и зарубежного происхождения и сортообразцов из богатой коллекции ВИР, обладающих ценными хозяйственно-биологическими признаками. В гибридизационной работе применяли широко распространенные в мировой практике методы традиционной селекции - синтетический и аналитический, межвидовая, межсортовая, отдаленная гибридизация, а позже - использование мутагенеза - физического и химического [3,5]

В конце 60-х и 70-е годы в прошлого столетия в НИИ Овощеводства и его ЗОС развернулась активная и весьма плодотворная работа по селекции овощных культур, в основном по томату, под руководством и непосредственном участии директора института, доктора биологических наук М.А. Мусаева. В результате селекционерами было получено большое количество сортов и гибридов томата с ценными биологическими, хозяйственными и технологическими качествами. Наличие многообразия исходного коллекционного материала и сортообразцов позволяло вести селекционную работу в нескольких направлениях, таких как получение столовых сортов для консервирования, промышленного производства томатопродуктов, а также для механизированной уборки и транспортабельных сортов. В течение ряда лет богатый селекционный материал (сорта и гибриды) тщательно изучались и апробировались в соответствующих питомниках. Лучшие из них, перспективные сорта и гибриды проходили дальнейшее изучение в питомнике конкурсного сортоиспытания с одновременным выращиванием их в питомниках семенного размножения для получения элитных и суперэлитных семян томата [2].

С целью создания высокоурожайных и высококачественных полноценных сортов, отвечающих основным требованиям, устойчивых к абиотическим факторам, болезням и вредителям, а также дальнейшего представления их в Госкомиссию для районирования, селекционеры строили свою работу в комплексе с сопредельными лабораториями. Так, агротехники занимались изучением технологии выращивания растений, а также режима орошения. В лаборатории физиологии и биохимии проводились исследования по влиянию абиотических факторов среды на рост и развитие растений, изучались показатели фотосинтеза, солеустойчивость и засухоустойчивость различных сортов томата.

Агрохимики определяли наиболее эффективные нормы, сроки и способы внесения органических и минеральных удобрений для повышения урожая и получения экологически чистой продукции. Консервированием, переработкой, хранением и изучением транспортабельности плодов томата занимались сотрудники лаборатории технологии и переработки овошей. Многолетними исследованиями по разработке схем полей размещения пасленовых культур в общей системе, а также по изучению влияния предшественников на урожайность перспективных сортов томата занимались сотрудники лаборатории севооборота овощных культур.

Для выявления устойчивости растений овощных культур и степени распространения наиболее опасных заболеваний в институте с 1987 года был организован сектор иммунитета, работа которого включена в научно-тематический план лаборатории селекции.

Необходимо отметить, что селекционная работа с овощными культурами проводилась на основе общепринятой методики ВИР им. Н.И. Вавилова. Методами исследований сектора иммунитета являются лабораторный и полевой, основанные на существующих методических указаниях ВИР по селекции сортов и гибридов томата для открытого и защищенного грунта [5]. В результате совместной работы с сектором иммунитета изучено и оценено большое количество исходного селекционного материала и перспективных сортов томата, из коих районировано 5 новых сортов для открытого грунта.

\section{Результаты исследования и их обсуждение}

В таблице приведены данные по некоторым морфологическим и биохимическим показателям новых районированных сортов томата. Как видно из этих данных, среди новых сортов Нуру и Азербайджан-94 отличаются высокорослостью (соответственно 25-80 и 75-85 см) и большой массой плодов (соответственно 157-172 и 180-190 г). По урожайности Азербайжан-94 и Мирвари превосходят остальные сорта томата (урожайность составляла соответственно 624,4-633,9 и 612,0625,2 ц/га). Все новые сорта томата отличаются устойчивостью к болезниям и к абиотическим факторам среды. 
По биохимическим показателям, по содержанию сухого вещества и суммы сахаров выделяются Азербайджан-94 (соответственно 6,4-6,8 и 2,7-3,3\%) и Мирвари (соответственно 6,2-6,7 и 2,6-3,3\%). Общая кислотнось у новых сортов томата колеблется в пределе 0,22-0,40\%. По содержанию аскорбиновой кислоты заметные различий не наблюдаются. Уровень нитратов в плодах томата варьирует в пределах 45-60 мг/кг, что гораздо меньше ПДК.

Ниже приводится краткая характеристика новых районированных сортов томата для открытого грунта.

Сорт Зарраби - получен путем скрещивания сложного гибрида (США (121) и 4). Растение детерминантного типа, полураскидистое, среднеоблиственное. Высота основного стебля 60-70 см. Листья обыкновенные, среднего размера, светло-зеленые, со слабогофрированной поверхностью. Плоды сорта плоскоокруглые (индекс $0,85-0,96)$ гладкие, красного цвета, без зеленого пятна. Поверхность кожицы глянцевая. Средняя масса товарного плода 145-160 г. Масса 1000 семян - 3-4 г. Сорт раннеспелый, от всходов до созревания плодов проходит 110-115 дней. Общая урожайность - 498,2-520,0 ц/га, товарная - 480,0-520,0 ц/га. За первые 15 дней плодоношения дает 26,3-27,0\% от общего урожая. Вкусовые качества плодов хорошие. Содержание сухого вещества в плодах - 5,5-5,7\%, общего сахара - 2,7-3,0\%, аскорбиновой кислоты - 28,0-29,8 мг/100 г, общая кислотность - 0,24-0,32\%. Сорт в полевых условиях устойчивый к основным болезням и неблагоприятным факторам среды. Сорт районирован в Азербайджане в 2011 году.

Сорт Нуру - получен путем скрещивания $4 \times 121$ (сложный гибрид США). Растение детерминантного типа, полураскидистое и среднеоблиственное. Высота главного стебля 65-80 см. Лист обыкновенный, среднего размера, светло-зеленый, глянцевый, слабогофривонный. Форма плода плоскоокруглая, гладкая. Окраска зрелого плода красная. Поверхность кожицы глянцевая. Тип гнезда неправильный. Масса 1000 ceмян 3-5 г. Число семян в плоде в среднем 50-125 штук. Масса товарного плода 156,5-172,0 г. Сорт среднеспелый, от всходов до созревания плодов проходит 105110 дней. Период плодоношения 75-95 дней. Общая урожайность - 520,0-532,3 ц/га, товарная - 439,4516,4 ц/га. Содержание сухого вещества в плодах 5,5-6,0\%, общего сахара - 2,4-2,6\%, аскорбиновой кислоты - 23,0-25,5 мг/100 г, общей кислотность $0,28-0,40 \%$. Среднеустойчив к фузариозному увяданию, хорошо переносит высокую температуру и низкую влажность воздуха. Лежкость и транспортабельность средняя. Сорт предназначен для потребления в свежем виде и для переработки с целью получения высококачественных томатных продуктов. Сорт районирован в 2009 году в Азербайджане.

Сорт Юбилей-60 - получен в Азербайджанском Научно-Исследовательском Институте овощеводства путем скрещивания Cito×5 (Гаратаг 256×L. Humbolt Mill). Растение детерминантного типа, среднеоблиственное и компактное. Высота главного стебля 55,0-61,0 см, а диаметр куста 50,0-55,0 см. Лист обыкновенный, крупный, длина листовой пластинки 25-28 см, ширина 6,5-8,0 см, зеленый, глянцевый, среднегофрированный. Форма плода овального типа, гладкая. Окраска незрелого плода зеленая с темным оттенком, а зрелего интенсивно красная. Раннеспелый, от массового прорастания до созревания первого плода проходит 89105 дней. Плод длинный, овальный, поверхность гладкая, цвет спелого плода - красный. Количество ячеек в плоде 2-3, трещин не образуется, семена в плоде средние. Урожайность сорта - 500,0-650,0 ц/га, товарная 450,0-600,0 ц/га. Масса плода 95,5-105,5 г. Химический состав плодов: сухое вещество - 5,0-6,0\%, сумма сахаров - 2,5-2,8\%, витамин C - 25,5-30,6 мг/100 г, общая кислотность - 0,36-0,38\%. Сорт устойчив к вирусным заболеваниям и абиотическим факторам среды,

Таблица 1. Некоторые морфологические и биохимические показатели сортов томата

Table 1. Some morphological and biochemical characteristics of tomato varieties

\begin{tabular}{|c|c|c|c|c|c|}
\hline \multirow{2}{*}{ Показатели } & \multicolumn{5}{|c|}{ Сорта } \\
\hline & Зарраби & Hypy & Юбилей-60 & Азербайджан-94 & Мирвари \\
\hline \multicolumn{6}{|c|}{ Морфологические показатели } \\
\hline Высота растений, см & $60-70$ & $65-80$ & $55-61$ & $75-85$ & 624,4 \\
\hline Масса плода, г & $145-160$ & $157-172$ & $96-106$ & $180-190$ & $100-105$ \\
\hline Масса 1000 семян, г & $3-4$ & $3-5$ & $3-3,5$ & $3-3,4$ & $2,8-3,1$ \\
\hline $\begin{array}{l}\text { Вегетационный период от массовых } \\
\text { всходов до созревания плодов }\end{array}$ & $110-115$ & $105-110$ & $89-105$ & $108-110$ & $109-115$ \\
\hline Форма плода & плоскоокруглые & плоскоокруглые & овальные & округлые & яйцевидные \\
\hline Урожайность, ц/га & $498,2-520,0$ & $520,0-532.3$ & $500-650$ & $624,4-633,9$ & $612,0-625,2$ \\
\hline Срок созревания & раннеспелый & среднеспелый & раннеспелый & среднеранний & среднеранний \\
\hline $\begin{array}{l}\text { Степень устойчивости к болезням и } \\
\text { абиотическим фактором среды }\end{array}$ & устойчивый & среднеустойчивый & устойчивый & устойчивый & устойчивый \\
\hline \multicolumn{6}{|c|}{ Биохимические показатели } \\
\hline Сухое вещество, \% & $5,5-5,7$ & $5,5-6,0$ & $5,0-6,0$ & $6,4-6,8$ & $6,2-6,7$ \\
\hline Сумма сахаров, \% & $2,7-3,0$ & $2,4-2,6$ & $2,5-2,8$ & $2,7-3,3$ & $2,6-3,3$ \\
\hline Общая кислотность, \% & $0,24-0,32$ & $0,28-0,40$ & $0,36-0,38$ & $0,30-0,33$ & $0,22-0,33$ \\
\hline Аскорбиновая кислота, мг/100 г & $28,0-29,8$ & $25,5-29,0$ & $25,5-30,6$ & $27,0-29,0$ & $25,0-28,0$ \\
\hline Нитраты, мг/кг & $45-55$ & $47-60$ & $50-60$ & $48-60$ & $47-60$ \\
\hline
\end{tabular}


пригоден для хранения. Сорт районирован в 2010 году в Азербайджане.

Сорт Азербайджан-94 получен путем скрещивания Гаратаг-256 х Оттава-30. Растения обыкновенные, детерминантные, полураскидистого типа. Высота растений - 75-85 см, среднеоблиственное. Лист обыкновенного типа, средней величины (12-16 см), окраска серо-зеленая. Завязываемость цветков высокая, плоды округлой формы (индекс 0,80-0,90), гладкие, без зеленого пятна, вершина плода с носиком. Масса плода - 180,0-190,0 г. Масса 1000 семян - 3,0-3,4 г. Среднеранний, от массовых всходов до биологической спелости плодов проходит 108-110 дней. Общая урожайность - 624,4-633,9 ц/га, за первые 15 дней плодоношения отдает 26,0-27,5\% от общего урожая. Вкусовые качества плодов - отличные. Биохимический состав плодов: сухое вещество - 6,4-6,8\%, общий сахар - 2,7-3,3\%, витамин C - 27,0-29,0 мг/100 г, общая кислотность - 0,30-0,33\%. Сорт высокоурожайный, транспортабельный, лежкий, устойчивый к фузариозу и другим болезням, отзывчив на удобрения. Сорт районирован в республике в 2017 году.

Сорт Мирвари - получен путем отбора из гибрида Хедвич в НИИ Овощеводства. Растения обыкновенные, детерминантные, полураскидистого типа, среднеоблиственное. Высота растений - 60-70 см. Лист картофельного типа, средней величины (20-25 см), окраска темно-зеленая. Завязываемость цветков высокая, плоды яйцевидной формы (индекс 1,0-1,2), гладкие, без зеленого пятна, вершина плода с носиком. Масса пло-

\section{ЛИТЕРАТУРА}

1. Абдуллаева Х.Т, Джафарова Т.Ф. Агробиологические особенности овощных культур (районированные сорта томата, баклажана, перца) для открытого грунта в условиях Азербайджана. Справочник овощевода АзНИИ Овощеводства. 3-е новое издание. Баку, 2006. С.44-46.

2. Каталог районированных и перспективных сортов овощных, бахчевых культур и картофеля. Азербайджанский Научно-Исследовательский Институт Овощеводства. Баку, "ASIM". 2012. $102 \mathrm{C}$.

3. Лессовой М.П., Пантелеев В.К. Ускорить создание устойчивых сортов. Защита растений. 1987;(4):62-63.

4. Мамедов М.И., Пивоваров В.Ф., Пышная О.Н. Селекция томата, перца и баклажана на адаптивность. Москва, 2002. $442 \mathrm{c}$.

5. Методические указания по селекции растениеводства и селекции сортов и гибридов томата для открытого и защищенного грунта. ВАСХНИЛ. Отделение растениеводства и селекции. М., 1986. 296 с.

\section{OБ АВTOPAX:}

Алиева Ирада Шавахат кызы, докторант

Агаев Фахраддин Нифи оглу, кандидат биологических наук да - 100,0-105,0 г. Масса 1000 семян - 2,8-3,1 г. Сорт среднеранний, от массовых всходов до биологической спелости плодов проходит 109-115 дней. Общая урожайность - 612,0-625,2 ц/га. Вкусовые качества плодов - отличные. Биохимический состав плодов: сухое вещество - 6,2-6,7\%, общий сахар - 2,6-3,3\%, витамин C - 25,0-28,0 мг/100 г, общая кислотность - 0,220,33\%. Сорт высокоурожайный, транспортабельный, лежкий, пригодны для длительного хранения, употребляется в свежем виде и для целей консервирования. Растения устойчивы к фузариозу и другим заболеваниям, в также к абиотическим условиям среды. Сорт районирован в республике в 2017 году.

\section{Выводы}

1. В результате многолетней селекционной работы нами созданы высокоурожайные и высококачественные сорта томата Зарраби, Нуру, Юбилей-60, Азербайджан-94 и Мирвари, районированные в республике в 2001-2017 годы. Эти сорта также устойчивые к болезням и абиотическим факторам среды, таким как засуха, высокая температура и низкая влажность воздуха.

2. Установлено, что среди нововыведенных сортов томата ноибольшей урожайности (612,0-633,9 ц/га) и высоким содержанием сухого вещества $(6,2-6,8 \%)$ и общего сахара $(2,6-3,3 \%)$ отличаются сорта Азербайджан-94 и Мирвари. Все новые сорта томата являются раннеспелыми и среднеранними, они предназначены и для столовых целей и для переработки с целью получения высококачественных пищевых продуктов.

\section{REFERENCES}

1. Abdullaeva Kh.T., Jafarova T.F. Agrobiological features of vegetable crops (zoned varieties of tomato, eggplant, pepper) for open ground in Azerbaijan. Directory of vegetable grower AzNII Vegetable. 3rd new edition. Baku, 2006. P.44-46. (In Russ.)

2. Catalog of zoned and promising varieties of vegetables, melons and potatoes. Azerbaijan Scientific Research Institute of Vegetable Growing. Baku, "ASIM". 2012. 102 p. (In Russ.)

3. Loessovoy M.P., Panteleev V.K. Accelerate the development of resistant varieties. Plant protection. 1987;(4):62-63. (In Russ.)

4. Mamedov M.I., Pivovarov V.F., Pyshnaya O.N. Selection of tomato, pepper and eggplant for adaptability. Moscow, 2002. 442 p. (In Russ.)

5. Guidelines for the selection of plant growing and selection of varieties and hybrids of tomato for open and protected ground. VASKHNIL. Department of Plant Growing and Breeding. M., 1986. 296 p. (In Russ.)

ABOUT THE AUTHORS:

Irada Sh. Aliyeva, doctoral student Fakhraddin N. Agayev, Cand. Sci. (Biology) 